\title{
Progress towards spin-polarized scanning tunneling microscopy
}

\author{
I. V. Shvets, ${ }^{\text {a) }}$ R. Wiesendanger, D. Bürgler, G. Tarrach, and H.-J. Güntherodt \\ Institut für Physik, Universität Basel, Klingelbergstrasse 82, CH-4056, Basel, Switzerland \\ J. M. D. Coey \\ Physics Department, Trinity College, Dublin 2, Ireland
}

(Received 20 September 1991; accepted for publication 6 February 1992)

Solutions to the main problems in operating a spin-polarized scanning tunneling microscope are discussed. Preliminary experimental results obtained in the course of implementing these solutions are reported. Atomic resolution on $\mathrm{Si}(111)$ and $\mathrm{Si}(100)$ is achieved with a scanning tunneling microscope (STM) using chromium and iron tips. Fabrication of antiferromagnetic tips of $\mathrm{Cr}, \mathrm{MnNi}$, and $\mathrm{MnPt}$ is described. A technique of preparation of clean (100) surfaces of $\mathrm{Fe}_{3} \mathrm{O}_{4}$ (magnetite) is given. Low-energy electron diffraction patterns were obtained on $\mathrm{Fe}_{3} \mathrm{O}_{4}$ for the first time. The first STM experimental results obtained on magnetite in air and in ultrahigh vacuum are reported. Atomic resolution is obtained on $\mathrm{Fe}_{3} \mathrm{O}_{4}(100)$ with an ultrahigh vacuum scanning tunneling microscope using iron and tungsten tips. This is the first successful observation of atomic resolution on a ferromagnetic sample using a ferromagnetic tip.

\section{INTRODUCTION}

Since the invention of the scanning tunneling microscope (STM) by Binnig, and co-workers in $1981,{ }^{1}$ this technique has become a powerful tool for surface science investigations. STM enables one to obtain atomic resolution in direct space. It is clear that the opportunity to resolve spins of separate ions on a surface could be a very valuable extension of the capabilitics of STM. In addition, it could possibly be used for extremely high density magnetic recording.

The theoretical background for the idea of spinpolarized scanning tunneling microscopy (SPSTM) is given in Ref. 2. It is shown that the tunnel current between two ferromagnetic layers depends on the relative orientation of magnetization of these ferromagnets. In early experimental work on magnetization dependent tunneling between two ferromagnetic films, published in $1975{ }^{3}$ the author observed the change in the tunnel current when an external magnetic field changed the relative orientation of magnetization in the films. Therefore, the most straightforward idea for SPSTM would be to establish a tunnel current between a ferromagnetic tip and a ferromagnetic sample, and to apply a magnetic field which changes the direction of magnetization in the sample, and to monitor a difference in the tunnel current. However, it is not easy to carry out this experiment for two main reasuns:

(i) Magnetostatic interaction of a ferromagnetic tip with a ferromagnetic sample. The direction of magnetization of the tip and the sample are linked. One can try to find a material for the tip with a large anisotropy in order to keep its magnetization fixed after the external magnetic field is applied. Nevertheless, during the experiment it would be difficult to change the magnetization of the sample with the confidence that the magnetization of the tip has not changed.

\footnotetext{
"Permanent address: Physics Department, Trinity College, Dublin 2, Ireland.
}

(ii) Magnetostriction. A change in the direction of magnetization in the sample may result in a change in its thickness also. Therefore, the tip-sample distance and the position of the tip over the sample change. Since a reasonable size of a sample is about $1 \mathrm{~mm}$, and the tunneling distance is about $10^{-7} \mathrm{~mm}$, it is clear that even a very small magnetostriction $\Delta l / l \approx 10^{-7}$ is not tolerable. This problem cannot be easily solved by using a thin magnetic film on a nonmagnetic substrate as a sample, and a composition tip: magnetic film sputtered onto the top of a nonmagnetic tip (e.g., $\mathrm{Pt} / \mathrm{Ir}$ or $\mathrm{W}$ ). Magnetostriction of a paramagnet is usually of the order of $\Delta l / l \approx 10^{-8}-10^{-6}$ in the external field of $1 \mathrm{kOe}$. For example, since the length of the tip with the tip holder is about $10 \mathrm{~mm}$, the tip point would move $\approx 0.1-10 \mathrm{~nm}$ after the external magnetic field is applied. To overcome problems (i) and (ii), we employ the following approach.

(1) To break the magnetostatic link between a tip and a sample, at least one of them must be an antiferromagnet. The advantage of an antiferromagnetic lip over a ferromagnetic one is that it would be more universal, i.e., it would be suitable for studying ferromagnetic and antiferromagnetic samples as well.

(2) To control the tip-sample distance and to get rid of problems with magnetostriction, one needs reference points on the surface. We suggest using a binary localized ferromagnetic compound with a nonmagnetic ion in the lattice as a probe surface. Corrugation between magnetic and nonmagnetic ions should be measured at two different orientations of magnetization. The corrugation should depend on the direction of magnetization since the tunnel current from the nonmagnetic ion should be independent of it. Thus nonmagnetic ions on the surface of the binary ferromagnet therefore serve as the reference points.

The first successful experiment with the tunneling between a ferromagnet (tip of $\mathrm{CrO}_{2}$ ) and an antiferromagnet (sample of $\mathrm{Cr}$ ) has already been performed in our laboratory. ${ }^{7}$ Calculations showing that the tunnel current between a ferromagnet and an antiferromagnet depends on 
TABLE I. Electrically conducting antiferromagnets with the Néel temperature above room temperature for use as SPSTM tip materials.

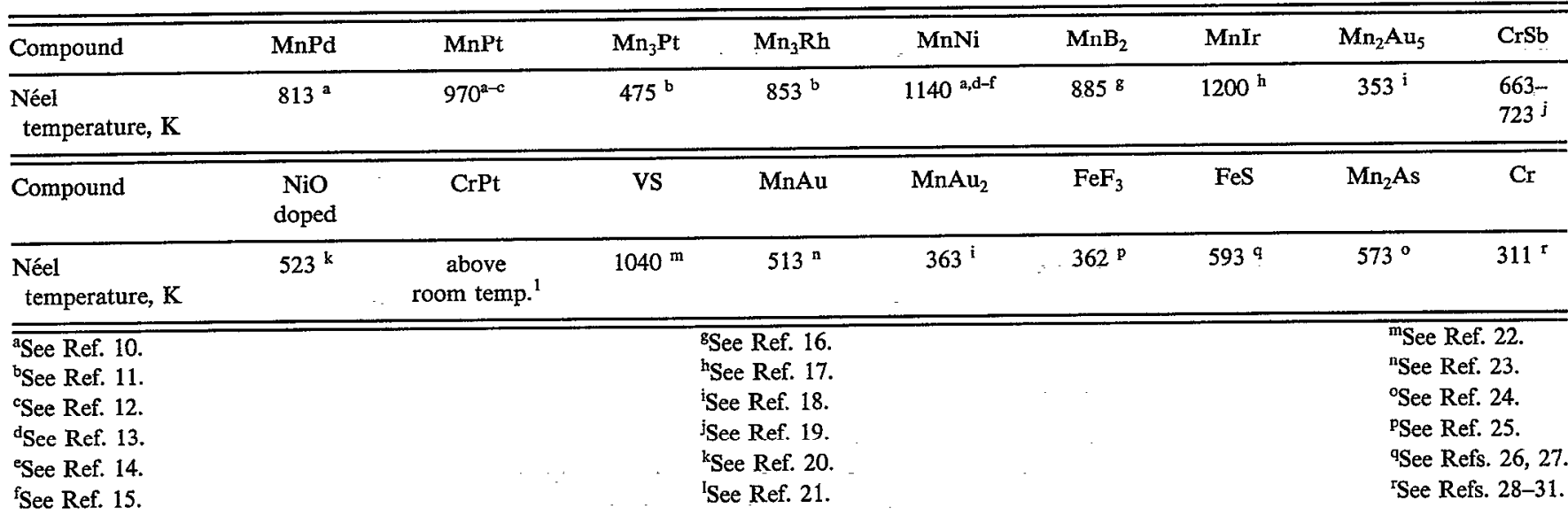

the relative orientation of the ferromagnetic and antiferromagnetic vectors, are given in Ref. 9.

In order to start spin-polarized STM experiments, one needs a bank of information about scanning tunneling microscopy with magnetic samples and magnetic tips. This work has just started. To our knowledge, no ferromagnetic samples have been successfully imaged with atomic resolution, except $\mathrm{Ni}^{4,5}$ There are also several STM investigations involving magnetic tips. ${ }^{6-8}$ Much more work is needed.

Progress towards a definitive experiment could come in three stages.

(1) Developing techniques for fabricating ferromagnetic and antiferromagnetic tips. Achievement of atomic resolution on a conventional surface [i.e., $\mathrm{Si}(111)]$ with a STM using a magnetic tip.

(2) Finding a technique for preparing the surface of a binary ferromagnet, clean and without contamination. Achievement of atomic resolution images on the ferromagnet with a STM using conventional (W or PtIr) tips.

(3) Combining a ferromagnetic or antiferromagnetic tip and a binary ferromagnetic sample. The work should include: measurements of corrugation at two different directions of the magnetization in the sample, and identifying the tips which are most sensitive to the spin polarization. This is the goal. Below we report preliminary cxperimental results of our systematic work along those lines. We also give a detailed list of antiferromagnets and binary ferromagnets which could be used in the SPSTM experiments as tips and samples, respectively.

\section{ANTIFERROMAGNETIC TIPS}

Since it is easier to carry out STM experiments at room temperature, the tip and the sample should have Néel and Curie temperatures above room temperature. In Table I we give a list of electrically conducting antiferromagnets with Néel temperatures higher than room temperature.

The following five alloys of $\mathrm{Mn}$ have extremely high Néel temperatures and magnetic moments: $\mathrm{MnNi}, \mathrm{MnPt}$, $\mathrm{MnPd}, \mathrm{MnAu}$, and MnIr. They are mechanically hard and resistant to oxidation. That is why we consider these alloys good candidates for STM tips. Of the single component antiferromagnets, only $\mathrm{Cr}$ has a Néel temperature above room temperature. As it is easier to make tips of chromium than binary compounds, we started our experiments using $\mathrm{MnPt}, \mathrm{MnNi}$, and $\mathrm{Cr}$ tips. More detailed information on these compounds is given below.

MnPt. At room temperature, the compound has a tetragonal $\mathrm{CuAu}-1$ phase (Fig. 1), ${ }^{10-12}$ with lattice parameters: $a=4.00 \AA$ and $c=3.67 \AA$. The $\mathrm{CuAu}-1$ phase is stable over a wide range of concentrations (33-60 at. \% $\mathrm{Pt}) .^{10}$ In a nonstoichiometric composition, the excess atoms generally occupy at random the positions in the sublattice of the other component. The magnetic and atomic unit cells are identical. The magnetic structure is collinear antiferromagnetic. ${ }^{10}$ The magnetic moment is $4.3 \mu_{B}$ per $\mathrm{Mn}$ atom; Pt has no moment. Neutron diffraction shows that the compound suffers a transition with a reorientation of spins by $90^{\circ}$. Below the transition the spins lie along the $c$ axis, and at higher temperatures along the [100] or [011] axes. The authors of Ref. 10 have not distinguished between the last two cases. The temperature, $T_{s}$, of the spinflip transition between the two phases is sensitive to deviations from stoichiometry. For stoichiometric $\mathrm{MnPt}$, $T_{s}=440^{\circ} \mathrm{C}$. On increasing the concentration of $\mathrm{Mn}, T_{s}$ increases. In order to exclude complications with the above transition, it is reasonable to use a compound with 50-52 at. \% $\mathrm{Mn}$ or $40-48$ at. \% $\mathrm{Mn}$. In the first concentration range, the temperature $T_{s}$ is much above room tempera-

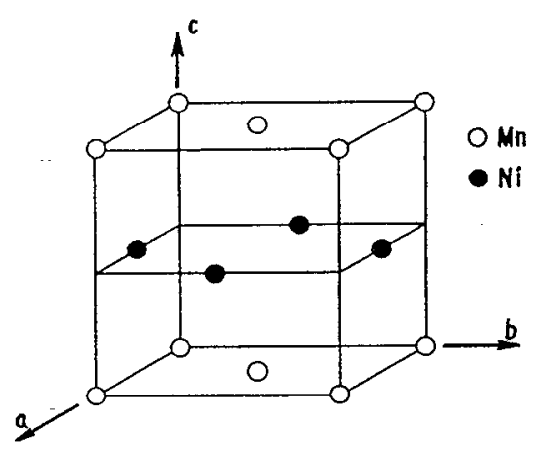

FIG. 1. The tetragonal structure of $\mathrm{MnNi}(\mathrm{MnPt})$. 


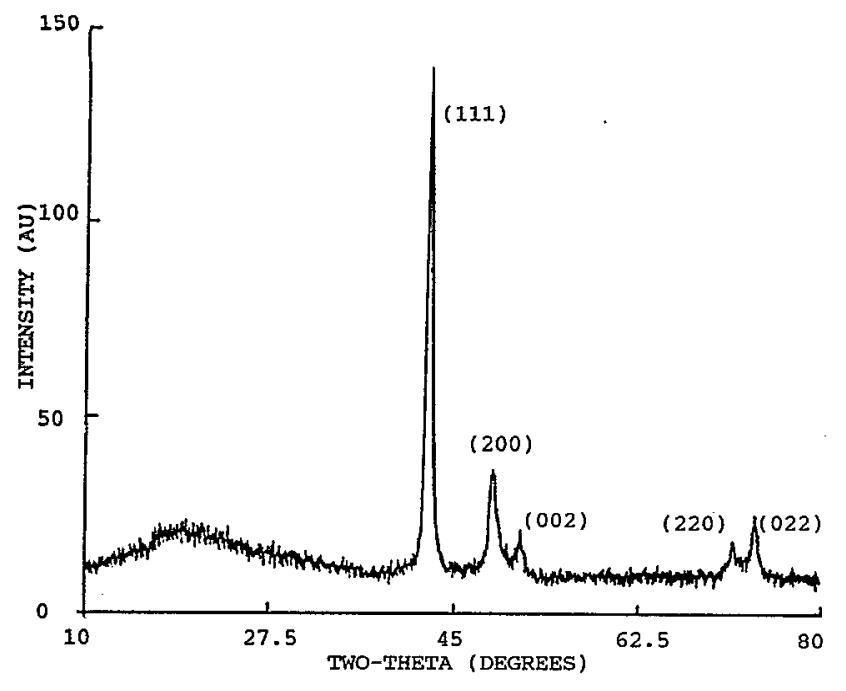

FIG. 2. X-ray diffractogram of MnNi. All the lines are identified with the structure of $\mathrm{MnNi}$.

ture. In the second one, no spin-flip transition is observed at all. ${ }^{11}$ The compounds MnPd and MnNi do not suffer such a transition. With decreasing temperature, the lattice of $\mathrm{MnPt}$ contracts along the $a$ and expands along the $c$ axis.

MnNi. The compound also has a tetragonal $\mathrm{CuAu}-1$ type crystal structure (Fig. 1). Lattice parameters are $a$ $=3.714 \AA$ and $c=3.524 \AA .{ }^{13}$ From sharp superlattice reflections in $x$-ray diffraction, one can conclude that the structure is well ordered. The homogeneity range is several atomic percent on either side of the equiatomic composition..$^{10,14,15}$ The results of neutron diffraction prove that the magnetic moment of $\mathrm{Ni}$ is zero. ${ }^{13}$ There are several models for spin configurations compatible with the results of neutron diffraction. In all of them, the spins of Mn are perpendicular to the tetragonal axis. The moment of the $\mathrm{Mn}$ ion is $4 \mu_{B}$. When the susceptibility is measured in a poor vacuum and at a high temperature, the surface oxidizes creating a ferromagnetic layer with a Curie temperature of $550 \mathrm{~K}$.

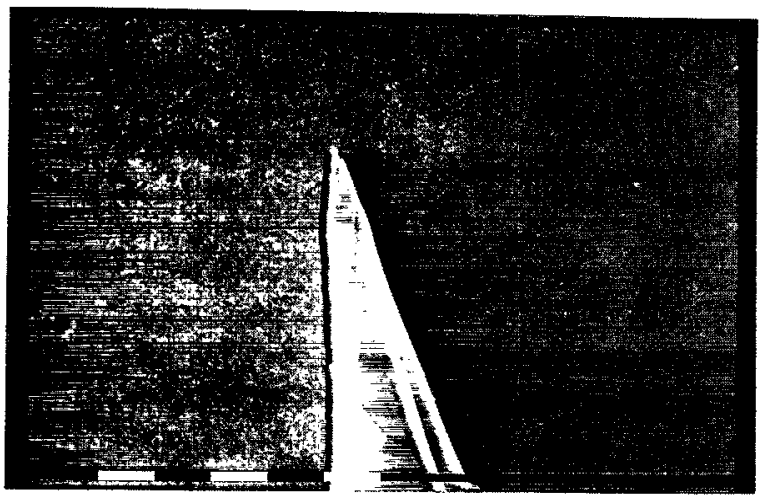

FIG. 3. Typical SEM appearance of a $\mathrm{Cr}$ tip prepared by electrochemical etching. White bar at the bottom of the figure corresponds to $1 \mu \mathrm{m}$.

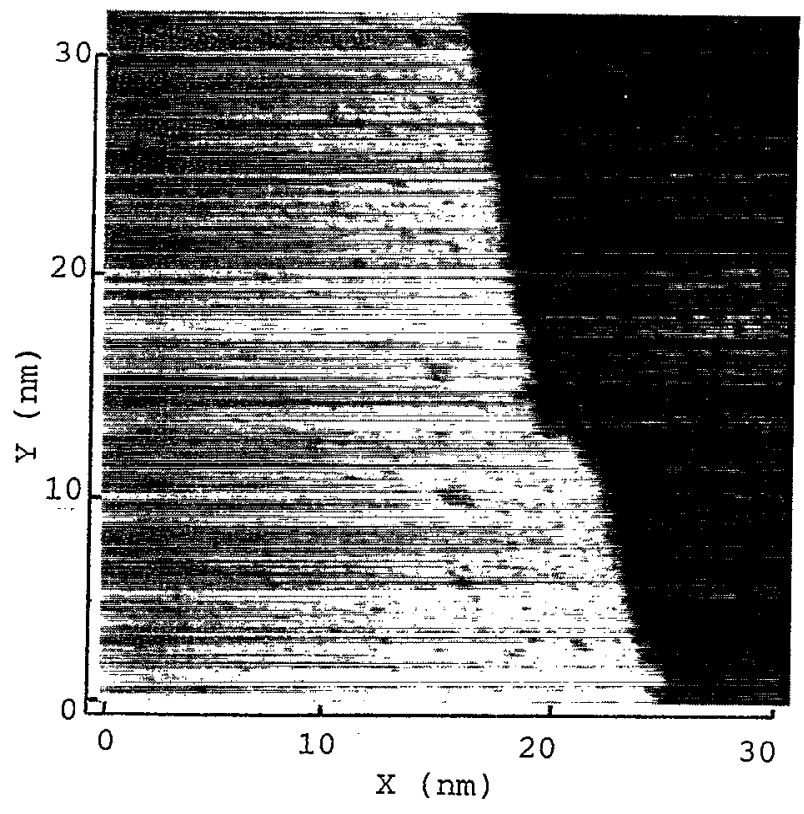

FIG. 4. Si(111) surface imaged with a UHV-STM using a $\mathrm{Cr}$ tip. Atomic resolution is achieved on both sides of a monoatomic surface step. The image is taken at a sample bias $2.0 \mathrm{~V}$, setpoint current $1 \mathrm{nA}$.

Cr. Chromium has magnetic structure of a spin density wave type. ${ }^{28}$ Experimental results ${ }^{29}$ and theoretical considerations $^{30,31}$ show that the spin density wave in chromium is not limited to the bulk only but extends up to its surface as well. Moreover, the amplitude of the spin density wave grows in the vicinity (1-5 $\AA$ ) of the surface plane. So, one can expect that the point of the STM tip of chromium may show the same antiferromagnetic structure as the bulk of the tip.

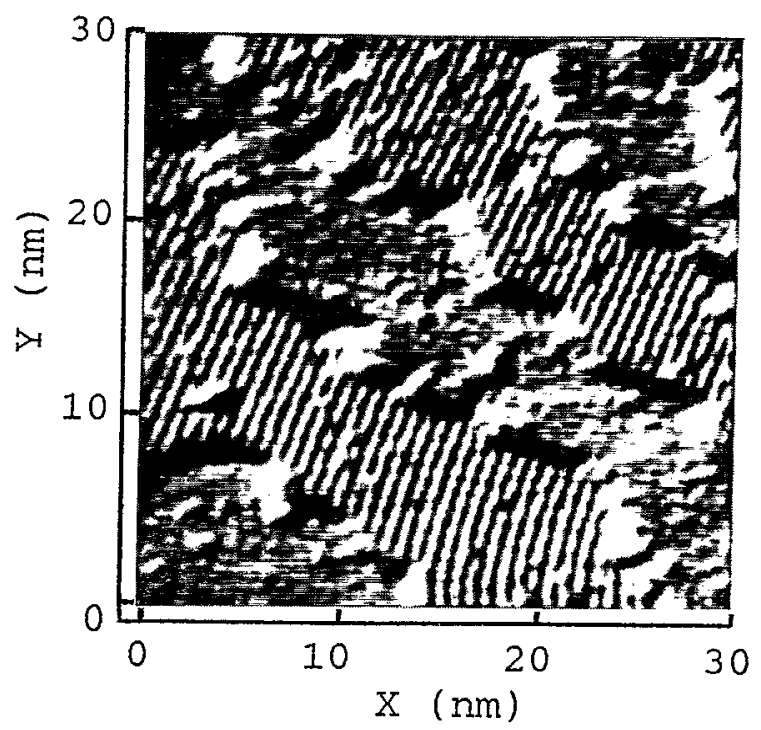

FIG. 5. Si(100) surface imaged with a UHV-STM using an iron tip. The tip was prepared in situ under UHV conditions. The dimer rows of the surface reconstruction $(2 \times 1)$, are clearly resolved. The image is taken at a sample bias of $2.5 \mathrm{~V}$, setpoint current is $1 \mathrm{nA}$. 
TABLE II. Electrically conducting binary ferromagnets for use as SPSTM samples.

\begin{tabular}{|c|c|c|c|}
\hline Compound & $\mathrm{Mn}_{5} \mathrm{Ge}_{3}$ & $\begin{array}{l}\text { Low-temperature } \\
\text { phase of } \mathrm{MnBi}\end{array}$ & $\mathrm{Mn}_{2} \mathrm{Sb}$ \\
\hline Crystal structure, symmetry & $D 8_{8}\left(p 6_{3} / \mathrm{m} \mathrm{cm}\right)$, hexagonal & NiAs-type structure, hexagonal & $\mathrm{P} 4 / \mathrm{nmm}$, tetragonal ${ }^{\mathrm{a}}$ \\
\hline $\begin{array}{l}\text { Lattice constants at room } \\
\text { temperature, } \AA\end{array}$ & $\begin{array}{l}c=5.053 \\
a=7.184\end{array}$ & $\begin{aligned} c & =6.12 \\
a & =4.29^{\circ}\end{aligned}$ & $\begin{array}{l}c=6.56 \\
a=4.08\end{array}$ \\
\hline Growth of the single crystals & The floating-zone technique ${ }^{c}$ & The growth is difficult ${ }^{\mathrm{d}}$ & By Czochralski technique \\
\hline $\begin{array}{l}\text { The range of the single-phase } \\
\text { homogeneity, at. } \%\end{array}$ & $\mathrm{Mn}, 35 \%-37 \%$ & & \\
\hline Easy cleavage plane & & & $(001)^{f}$ \\
\hline Curie temperature, $\mathrm{K}$ & $304^{h, i}$ & $753^{\mathrm{d}, \mathrm{g}}$ & 823 \\
\hline $\begin{array}{l}\text { The number of } \\
\text { magnetic sublattices }\end{array}$ & $\begin{array}{l}\text { Two sublattices with } \\
\text { collinear magnetization }\end{array}$ & One & $\begin{array}{l}\text { Two sublattices with } \\
\text { opposite magnetization }\end{array}$ \\
\hline $\begin{array}{l}\text { Magnetic moments for } \\
\text { different sublattices } \mu_{B}\end{array}$ & $\begin{array}{l}\mathrm{Mn}_{1}, 1.96 ; \\
\mathrm{Mn}_{2}, 3.23^{\mathrm{j}}\end{array}$ & $3.95^{\mathrm{d}}$ & $\begin{array}{c}\operatorname{Mn}(2 a \text { positions })-1.48 \\
\operatorname{Mn}(2 c \text { positions }) 2.66\end{array}$ \\
\hline Mössbauer nuclear field, $\mathrm{kOe}$ & $\begin{array}{l}\mathrm{Mn}_{1}, 195 \\
\mathrm{Mn}_{2}, 399^{\mathrm{k}}\end{array}$ & & \\
\hline $\begin{array}{l}\text { Magnetocrystalline } \\
\text { anisotropy, } \mathrm{erg} / \mathrm{cm}^{2}\end{array}$ & $10^{6}$ at $4 \mathrm{~K}$ & $10^{7}$ at room temperature ${ }^{d}$ & $7.5 \times 10^{5}$ at $400 \mathrm{~K}$ \\
\hline $\begin{array}{l}\text { Axis of easy magnetization } \\
\text { at room temperature }\end{array}$ & Hexagonal axis ${ }^{1}$ & Hexagonal axis & $c$ axis \\
\hline $\begin{array}{l}\text { Comments, additional } \\
\text { information }\end{array}$ & $\begin{array}{l}\text { A part of the moment of about } \\
0.1 \mu_{B} \text { per } \mathrm{Mn} \text { ion is delocalized and } \\
\text { opposite to the localized } \mathrm{Mn} \\
\text { moments. }\end{array}$ & $\begin{array}{l}\text { At } 360^{\circ} \mathrm{C} \text {, the phase undergoes a } \\
\text { transition to a high temperature phase. } \\
\text { The ferromagnetism disappears } \\
\text { at this temperature. }\end{array}$ & $\begin{array}{l}\text { About } 5 \% \text { of the total spin } \\
\text { density is delocalized. }{ }^{\mathrm{a}} \\
\text { Metallic dependence of the } \\
\text { conductivity vs temperature. }\end{array}$ \\
\hline
\end{tabular}

asee Ref. 41.

'See Ref. 40.

'See Ref. 32.

${ }^{\text {dSee Ref. } 38 .}$

eSee Ref. 42.

See Ref. 43.

\section{A. Fabrication and use of antiferromagnetic tips}

The fabrication of $\mathrm{MnPt}$ and $\mathrm{MnNi}$ tips is as follows. The appropriate amounts of $\mathrm{Mn}$ and $\mathrm{Pt}(\mathrm{Mn}$ and $\mathrm{Ni}$ ) are arc melted. The ingot is sealed in a quartz tube and annealed at $850^{\circ} \mathrm{C}$ for $20 \mathrm{~h}$. No losses of weight of the ingot during annealing are observed. Then the sample is cut into slices and checked by x-ray diffractometry (Fig. 2). The slices are cut into rods and the STM tips are fabricated in a standard way by electrochemical etching. ${ }^{6}$ The $\mathrm{Cr}$ tips were etched using $10 \% \mathrm{KOH}$ solution. The $\mathrm{MnNi}$ tips were etched using $5 \% \mathrm{HCl}$ solution. $20 \%$ aqueous solution of $\mathrm{KCN}$ was used for the etching MnPt tips. Pt wire was used as a cathode. The typical SEM appearance of such a tip is presented in Fig. 3. The radius of curvature of the tip is less than $100 \AA$, which is the resolution limit of the SEM. We have also developed a technique for preparation of clean and microscopically sharp tips in situ, in the ultrahigh vacuum (UHV) chamber at a background pressure of $1 \times 10^{-11}$ mbar. $^{6}$ The preparation technique is as follows. A rod of $\mathrm{Cr}, \mathrm{Fe}, \mathrm{MnNi}$, etc., is electrochemically etched
sSee Ref. 39.

${ }^{\text {hSee Ref. } 33 .}$

iSee Ref. 34.

iSee Ref. 35.

${ }^{\mathrm{k}} \mathrm{See}$ Ref. 36.

${ }^{1}$ See Ref. 37. until a constriction of $20-100 \mu \mathrm{m}$ diameter is formed. The top part is then fixed in the tip holder of the STM whereas the bottom part is fixed in another tip holder on top of a standard sample holder. The two parts can finally be pulled apart in the UHV chamber. The microtips formed at the very end of tips, reproducibly have a radius of curvature of $100 \AA$ or even less. The formation of the microtips with such a small radius of curvature does not depend on the diameter of the original constriction. Atomic resolution on $\mathrm{Si}(111)$ and $\mathrm{Si}(100)$ was routinely achieved using these tips (Figs. 4 and 5).

\section{B. Ferromagnetic samples for SPSTM}

A ferromagnetic sample for SPSTM should meet the following criteria:

(1) It should be binary and one of the two kinds of atoms should be nonmagnetic.

(2) Magnetic moments should be largely localized on the magnetic atoms. 
TABLE III. Electrically conducting binary ferromagnets for use as SPSTM samples.

\begin{tabular}{|c|c|c|c|}
\hline Compound & $\mathrm{MnSb}$ & $\gamma-\mathrm{Fe}_{4} \mathrm{~N}$ & $\mathrm{Fe}_{2} \mathrm{~B}$ \\
\hline Crystal structure, symmetry & $\begin{array}{l}\text { NiAs-type structure, } \\
\text { hexagonal } a, b\end{array}$ & $\begin{array}{l}\text { Perovskite-type structure, } \mathrm{fcc}^{\mathrm{c}, \mathrm{d}} \\
\qquad a=3.795\end{array}$ & $\begin{array}{l}C-16, \mathrm{CuAl}_{2} \text {-type } \\
\text { structure, tetragonal }\end{array}$ \\
\hline $\begin{array}{l}\text { Lattice constants } \\
\text { at room temperature, } \AA\end{array}$ & $\begin{array}{l}c=5.789 \\
a=4.130\end{array}$ & & $\begin{array}{c}c=4.249 \\
a=5.109^{\mathrm{d}, \mathrm{e}}\end{array}$ \\
\hline Growth of the single crystals & By Bridgman method & The growth is difficult $\mathrm{c}, \mathrm{g}$ & $\mathrm{h}, \mathbf{i}$ \\
\hline Melting point, $\mathrm{K}$ & $1080^{f}$ & & \\
\hline Curie temperature, $\mathrm{K}$ & $-588-600 \mathrm{~d}, \mathrm{f}$ & $761^{d, c}$ & 1015 \\
\hline The number of magnetic sublattices & One & $\begin{array}{c}\text { Two sublattices with collinear } \\
\text { magnetization of } \\
2.98 \text { and } 2.01^{\mathrm{k}}\end{array}$ & One \\
\hline $\begin{array}{l}\text { Magnetic moments for different } \\
\text { sublattices, } \mu_{B}\end{array}$ & $4.0^{\mathrm{f}, \mathrm{j}}$ & & 1.9 \\
\hline Mössbauer nuclear field, kOe & & 340 and 217 & \\
\hline Magnetocrystalline anisotropy, $\mathrm{erg} / \mathrm{cm}^{3}$ & $10^{6}$ at room temperature ${ }^{1}$ & Less than $3 \times 10^{6} \mathrm{c}$ & $4 \times 10^{6} \mathrm{~m}$ \\
\hline $\begin{array}{l}\text { Axis of easy magnetization } \\
\text { at room temperature }\end{array}$ & $\begin{array}{l}a-a \text { plane is the plane } \\
\text { of easy magnetization }\end{array}$ & $(100)$ & $\begin{array}{l}\text { The easy axis is } \\
\text { perpendicular to the } c \text { axis }{ }^{n}\end{array}$ \\
\hline Comments, additional information & $\begin{array}{l}\text { Magnetic moments } \\
\text { are localized. } \\
\text { Moment }-0.3 \mu_{B} \text { is } \\
\text { ascribed to } \mathrm{Sb} \text { ion }^{\mathrm{f}, \mathrm{j}}\end{array}$ & $\begin{array}{l}\text { The material is not stable and } \\
\text { slowly dccomposes in air }\end{array}$ & The Fermi level crosses the $d$ band ${ }^{\text {h }}$ \\
\hline $\begin{array}{l}\text { "See Ref. } 46 . \\
\text { bSee Ref. } 49 . \\
\text { 'See Ref. } 50 . \\
\text { 'See Ref. } 44 . \\
\text { 'See Ref. } 53 . \\
\text { See Ref. } 45 . \\
\text { 'See Ref. } 51 .\end{array}$ & . & $\begin{array}{l}{ }^{\mathrm{h}} \text { See Ref. } 54 . \\
\text { i See Ref. } 56 . \\
\text { j See Ref. } 47 . \\
\text { S See Ref. } 52 . \\
{ }^{\mathrm{k}} \text { See Ref. } 48 . \\
{ }^{1} \text { See Re. } \\
{ }^{\mathrm{m}} \text { See Ref. } 55 . \\
{ }^{\mathrm{n}} \text { See Ref. } 57 .\end{array}$ & \\
\hline
\end{tabular}

(3) Its Curie temperature, $T_{c}$, should be higher than room temperature.

(4) It should be electrically conducting.

(5) Its anisotropy should not be too large, to facilitate rotation of the magnetization with an external magnetic field which can be relatively easily achieved in UHV.

(6) To minimize tunneling of nonpolarized $s$ electrons there should be a high density of spin-polarized electrons at the Fermi surface, or at least the spin-polarized band should not be far below $E_{F}$.

As a rule, in binary compounds of transition metals, the spin-polarized $d$ band is close to the Fermi surface. Therefore, the magnetic ion should be a transition metal. In Table II, III, IV, V, and VI we list some ferromagnets which mect the criteria discussed.

The following compounds satisfy the above criteria the best: $\mathrm{Fe}_{3} \mathrm{O}_{4}, \mathrm{Fe}_{3} \mathrm{Si}, \mathrm{Fe}_{3} \mathrm{C}, \mathrm{MnSb}, \mathrm{Mn}_{2} \mathrm{Sb}$. Here we focus on $\mathrm{Fe}_{3} \mathrm{O}_{4}$.

\section{Magnetite}

$\mathrm{Fe}_{3} \mathrm{O}_{4}$ (magnetite) has attracted the attention of a large number of researchers because the compound is a common, naturally occurring magnetic mineral. It is an excellent material for understanding phenomena of fundamental importance in magnetism ${ }^{74,75}$ and it has important practical applications. ${ }^{72,73}$ The compound has the cubic inverse spinel structure (space group $\mathrm{O}_{h}^{7}$ ) at a temperature above the Verwey transition temperature $T_{v}$, and orthorhombic structure below this temperature. ${ }^{76}$ The lattice parameter at room temperature is $a=8.394 \AA .^{49}$ In the spinel structure, cations occupy $\mathbf{A}$ and $\mathbf{B}$ sites possessing tetrahedral and octahedral symmetry, respectively. The valence structure of magnetite is $\left[\mathrm{Fe}^{3+}\right]\left(\mathrm{Fe}^{3+} \mathrm{Fe}^{2+}\right)\left(\mathrm{O}^{2-}\right)$. Half of the $\mathrm{Fe}^{3+}$ ions (noted as $\left.\left[\mathrm{Fe}^{3+}\right]\right)$ are on tetrahedral sites and the other half [noted as $\left(\mathrm{Fe}^{3+}\right)$ ] on octahedral sites whereas all $\mathrm{Fe}^{2+}$ ions are located on octahedral sites. Electronic charge fluctuations $\mathrm{Fe}^{2+} \leftrightarrow \mathrm{Fe}^{3+}$ occur on B sites at room temperature but these ions create a superlattice below $T_{v}{ }^{77,78} \mathrm{Mag}-$ netite therefore undergoes an insulator-to-conductor transition at $T_{v}$. For a stoichiometric compound $T_{v}$ is 119 $\mathrm{K}$. Verwey temperature $T_{v}$ changes from 124 to $81 \mathrm{~K}$, as the parameter $\delta$ in $\mathrm{Fe}_{3(1-\delta)} \mathrm{O}_{4}$ increases from -0.0005 to $0.012 .^{79}$

$\mathrm{Fe}_{3} \mathrm{O}_{4}$ is a ferrimagnet with a Curie temperature $T_{c}=850 \mathrm{~K} .{ }^{76}$ Magnetic moments of the ions occupying the octahedral and the tetrahedral sites, are opposite (Fig. 6).

Magnetic moment of $5 \mu_{B}$ is ascribed to $\mathrm{Fe}^{3+}$ ions and 
TABLE IV. Electrically conducting binary ferromagnets for use as SPSTM samples.

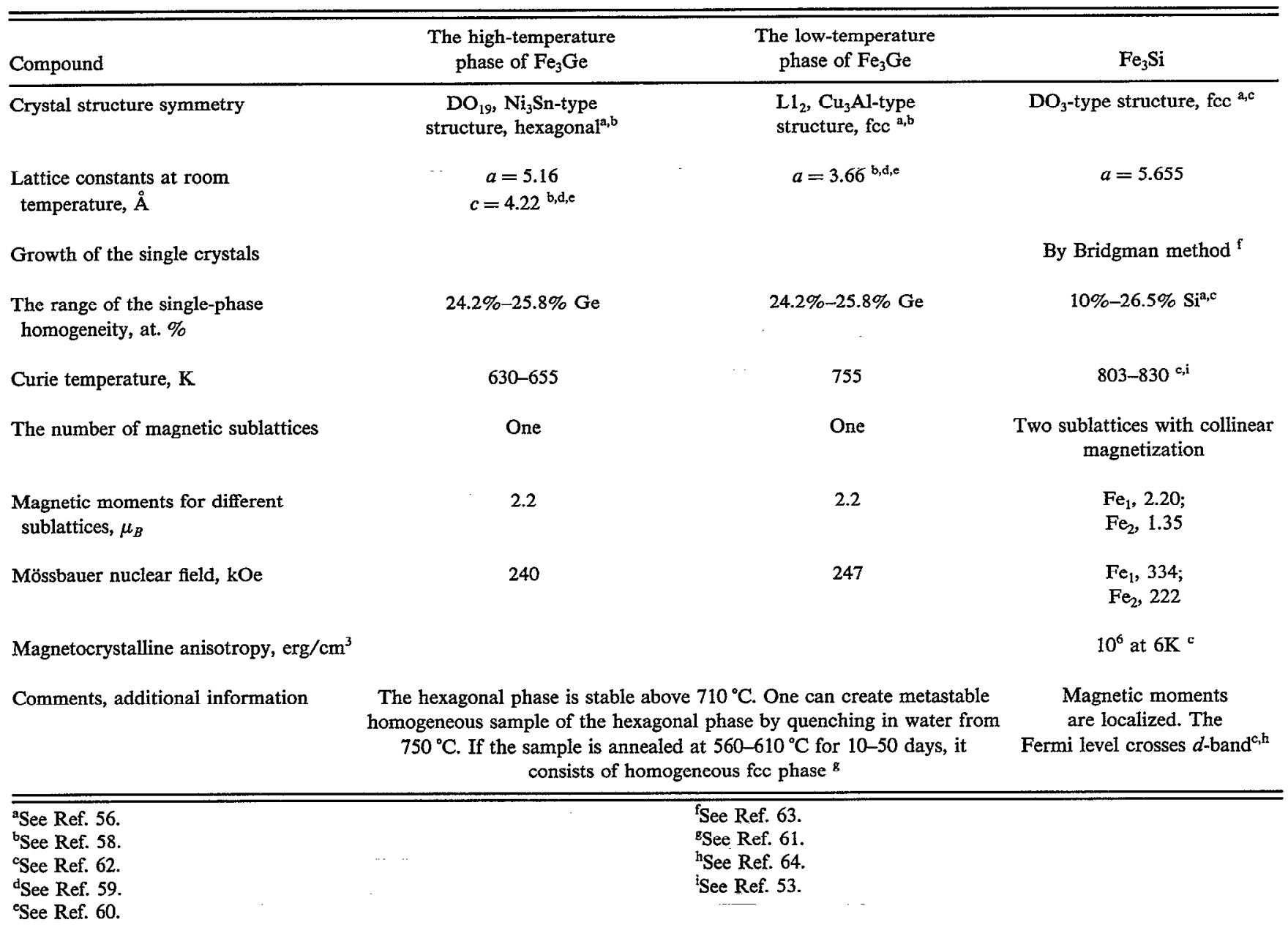

$4 \mu_{B}$ to $\mathrm{Fe}^{2+}$ ions. Thus the total moment of $\mathrm{Fe}_{3} \mathrm{O}_{4}$, is $4 \mu_{B}$ per formula unit. It was calculated ${ }^{80}$ that the band structure of $\mathrm{Fe}_{3} \mathrm{O}_{4}$ contains a gap in the majority spin band at the Fermi level but there is no gap in the minority spin band. It was found that the spin-polarization of photoelectrons from $\mathrm{Fe}_{3} \mathrm{O}_{4}$ has a large negative value of $-40 \%$ at $0.5 \mathrm{eV}$ below the photothreshold. ${ }^{75}$ Due to this fact we expect that $\mathrm{Fe}_{3} \mathrm{O}_{4}$ is a promising object for SPSTM.

In our experiments, we used natural single crystals of magnetite from different sources: Arizona (USA), Zillertal (Austria), and Queensland (Australia). Before starting the work on the surface preparation, we characterized the samples carefully by $\mathrm{x}$-ray diffractometry and measurements of resistance versus temperature. Eventually we selected single crystals from Zillertal for our surface investigations. These single crystals do not contain any traces of $\alpha-\mathrm{Fe}_{2} \mathrm{O}_{3}, \mathrm{Fe}$ or $\mathrm{FeO}$ in x-ray diffractograms. Their Verwey transformation is at $98 \mathrm{~K}$. Thus we conclude that the samples have a small deviation from stoichiometry $\delta \approx 0.005$. $^{79}$

\section{Preparation of clean (100) surfaces of magnetite}

It is well known that the different iron oxides ( $\mathrm{FeO}$, $\mathrm{Fe}_{3} \mathrm{O}_{4}, \alpha-\mathrm{Fe}_{2} \mathrm{O}_{3}, \gamma-\mathrm{Fe}_{2} \mathrm{O}_{3}$ ) can transform into each other after annealing in an appropriate partial pressure of oxygen. ${ }^{72}$ That is why we are particularly anxious to preserve the stoichiometry of the surface of magnetite under investigation. When exposed to air, the surface of magnetite is found always covered with hydrocarbons. The presence of carbon on the surface is indicated by Auger spectroscopy [Fig. 7(a)]. The amount of carbon does not seem to depend on the way the surface is prepared. After washing in organic solvents, the mechanically polished surface shows the same level of carbon contamination as the surface cleaved in air. The surface of magnetite cannot be cleaned by ion etching since this procedure changes the magnetic properties of the surface. ${ }^{81} \mathrm{We}$ have found that annealing at a temperature below $500^{\circ} \mathrm{C}$ in a vacuum of $10^{-10} \mathrm{mbar}$ increases the amount of carbon on the surface [Fig. $7(\mathrm{~b})]$ but annealing at $700^{\circ} \mathrm{C}$ for $20 \mathrm{~h}$ removes the carbon from the surface [Fig. $7(\mathrm{c})$ ]. Further annealing at $800^{\circ} \mathrm{C}$ for $20 \mathrm{~h}$ leads to the diffusion of impurities $\mathrm{K}$ and $\mathrm{Ca}$ from the bulk to the surface [Fig. 7(d)]. The spurious peaks at $80-120 \mathrm{eV}$ in Fig. 7 (d) are due to surface contamination with $\mathrm{K}$ and $\mathrm{Ca}$. Annealing does not change the relative intensities of the Auger lines of iron and oxygen. This means that the stoichiometry on the surface does not change. ${ }^{82}$ Thus we conclude that annealing at $700-750^{\circ} \mathrm{C}$ is the preferred way of preparing the surface of magnetite. 
TABLE V. Electrically conducting binary ferromagnets for use as SPSTM samples.

\begin{tabular}{|c|c|c|}
\hline Compound & $\mathrm{FeBe}_{2}$ & $\mathrm{Fe}_{3} \mathrm{C}$ \\
\hline $\begin{array}{l}\text { Crystal } \\
\text { structure, } \\
\text { symmetry }\end{array}$ & $\begin{array}{c}\text { Laves phase } C_{14} \\
\mathrm{MgZn}_{2} \text {-type structure, } \\
\text { hexagonal }\end{array}$ & $\begin{array}{c}\mathrm{DO}_{11} \text {-type } \\
\text { structure, } \\
\text { orthorhombic }\end{array}$ \\
\hline Lattice constants & $c=6.867$ & $c=6.743$ \\
\hline $\begin{array}{l}\text { at room } \\
\text { temperature, } \AA\end{array}$ & $a=4.220$ & $\begin{array}{c}a=4.525 \\
b=5.087^{\mathrm{a}}\end{array}$ \\
\hline $\begin{array}{l}\text { Growth of the } \\
\text { single crystals }\end{array}$ & & $\begin{array}{l}\text { Growth of the single } \\
\text { crystalline flakes } \\
50-100 \mu \mathrm{m} \text { in sizc } \\
\text { is described }\end{array}$ \\
\hline $\begin{array}{l}\text { Curie } \\
\text { temperature, } \mathbf{K}\end{array}$ & $823-930^{b, c}$ & $483^{\mathrm{a}}$ \\
\hline $\begin{array}{l}\text { The number of } \\
\text { magnetic sublattices }\end{array}$ & One & One \\
\hline $\begin{array}{l}\text { Magnetic moments } \\
\text { for different } \\
\text { sublattices, } \mu_{B} \text {. }\end{array}$ & $1.95^{\mathrm{d}}$ & $1.78^{b}$ \\
\hline $\begin{array}{l}\text { Mössbauer nuclear } \\
\text { field, } \mathrm{kOe}\end{array}$ & & 205 \\
\hline $\begin{array}{l}\text { Magnetocrystalline } \\
\text { anisotropy, } \\
\mathrm{erg} / \mathrm{cm}^{3}\end{array}$ & $\begin{array}{l}2 \times 10^{6} \text { at low } \\
\text { temperature }\end{array}$ & . \\
\hline $\begin{array}{l}\text { Comments, } \\
\text { additional } \\
\text { information }\end{array}$ & $\begin{array}{l}\text { Unusual ferromagnet. } \\
\text { It is predicted } \\
\text { that } \mathrm{FeBe}_{2} \text { is } \\
\text { micromagnet, and } \\
\text { in fact, } T_{c} \text { is its } \\
\text { freezing temperature }\end{array}$ & $\begin{array}{l}\text { The most stable phase } \\
\text { of iron carbides. } \\
\text { Hexagonal and } \\
\text { orthorhombic } \\
\text { phases of } \mathrm{Fe}_{2} \mathrm{C} \text { are } \\
\text { not stable }\end{array}$ \\
\hline
\end{tabular}

See Ref. 67.

bsee Ref. 44.

'See Ref. 53.

${ }^{d}$ See Ref. 65.
eSee Ref. 66.
fSee Ref. 56.

\section{LEED investigations on (100) surface of magnetite}

The easy cleavage plane of magnetite is (100). Ambient STM measurements showed that the polished (100) surface is more flat than the (111) surface on a nanometer scale. That is why we expect to obtain low energy electron diffraction (LEED) patterns on the polished (100) surface after it was cleaned by the annealing. LEED patterns on the (100) surface are reproducibly obtained (Fig. 8). The positions of the LEED spots have fourfold symmetry and are identified within an experimental systematical error of $10 \%$, with a cubic lattice having a lattice constant of a/ $\sqrt{2}=5.93 \AA$, where $a$ is the lattice constant of magnetite. It is understood as far as $a / \sqrt{2}$ is the lattice constant of a top layer of a(100) surface of magnetite along any cross section: $A_{1}, A_{2}$, or $A_{3}$ (Fig. 6).

The (111) surface of magnetite, mechanically polished in the same way as the (100) surface, shows only diffuse LEED pattern without any traces of diffraction spots. We also obtain LEED patterns on the (100) surface of magnetite cleaved in situ at a base pressure of $10^{-10} \mathrm{mbar}$ without any subsequent heat treatment. The patterns coincide with those obtained on the mechanically polished surface. This coincidence gives us a confidence that the mechanically polished (100) surface of magnetite does not suffer any changes in stoichiometry during polishing and annealing in UHV.
TABLE VI. Electrically conducting binary ferromagnets for use as SPSTM samples.

\begin{tabular}{|c|c|c|}
\hline Compound & $\mathrm{Fe}_{3} \mathrm{Sn}$ & $\mathrm{CrO}_{2}$ \\
\hline $\begin{array}{l}\text { Crystal } \\
\text { structure, } \\
\text { symmetry }\end{array}$ & $\begin{array}{l}\mathrm{DO}_{19} \text {-type } \\
\text { structure }^{\mathrm{a}}\end{array}$ & $\begin{array}{c}\mathrm{SnO}_{2} \text {-type structure, } \\
\text { space group } D_{4 h}^{14} \\
\text { tetragonal }\end{array}$ \\
\hline $\begin{array}{l}\text { Lattice } \\
\text { constants at room } \\
\text { temperature, } \AA\end{array}$ & & $\begin{array}{c}c=2.916 \\
a=4.421^{\mathrm{d}}\end{array}$ \\
\hline $\begin{array}{l}\text { Curie } \\
\text { temperature, } \mathrm{K}\end{array}$ & $743^{b}$ & $392^{e}$ \\
\hline $\begin{array}{l}\text { The number of } \\
\text { magnetic sublattices }\end{array}$ & One & One \\
\hline $\begin{array}{l}\text { Magnetic moments } \\
\text { for different } \\
\text { sublattices, } \mu_{B}\end{array}$ & $1.90^{\mathrm{b}}$ & $2.0^{\mathrm{c}}$ \\
\hline $\begin{array}{l}\text { Mössbauer nuclear } \\
\text { field, kOe }\end{array}$ & $250^{a}$ & \\
\hline $\begin{array}{l}\text { Magnetocrystalline } \\
\text { anisotropy, } \mathrm{erg} / \mathrm{cm}^{3}\end{array}$ & & $3 \times 10^{5 f}$ \\
\hline $\begin{array}{l}\text { Comments, } \\
\text { additional } \\
\text { information }\end{array}$ & $\begin{array}{l}\text { The phase is stable } \\
\text { between } 750 \text { and } \\
850^{\circ} \mathrm{C} \text {. Metastable } \\
\text { compound can be } \\
\text { obtained at room } \\
\text { temperature by } \\
\text { quenching the sample } \\
\text { from } 800^{\circ} \mathrm{C}\end{array}$ & $\begin{array}{c}\text { Electrons with the } \\
\text { binding energies } \\
2 \mathrm{eV} \text { below } E_{F} \text { have } \\
\text { nearly } 100 \% \text { spin } \\
\text { polarization }\end{array}$ \\
\hline
\end{tabular}

asee Ref. 69.

'See Ref. 68.

'See Ref. 49.
${ }^{\mathrm{d}}$ See Ref. 70.

'See Ref. 71.

See Ref. 44.
It is interesting to note that the UHV conditions are essential to prepare a surface of magnetite free from carbon contamination. For comparison, we have also cleaved magnetite under HV conditions with a base pressure in the cleavage chamber of $10^{-8} \mathrm{mbar}$. The sample remained in the cleavage chamber for only $3 \mathrm{~min}$ before being transferred to the UHV analysis chamber. Auger analysis showed that the surface of the sample contained the same level of carbon contamination as the surface of the sample cleaved in air, or mechanically polished.

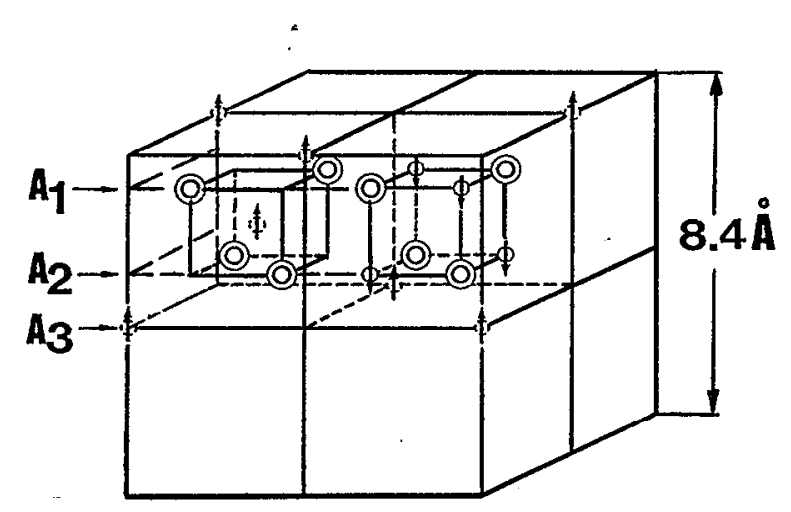

FIG. 6. Crystal structure and spin structure of $\mathrm{Fe}_{3} \mathrm{O}_{4}$. The size of the unit cell is $a=8.4 \AA$. $\Phi$ : Octahedral interstices; $\Phi:$ Tetrahedral interstices; (Q): $\mathrm{O}^{2-}$ ions. 

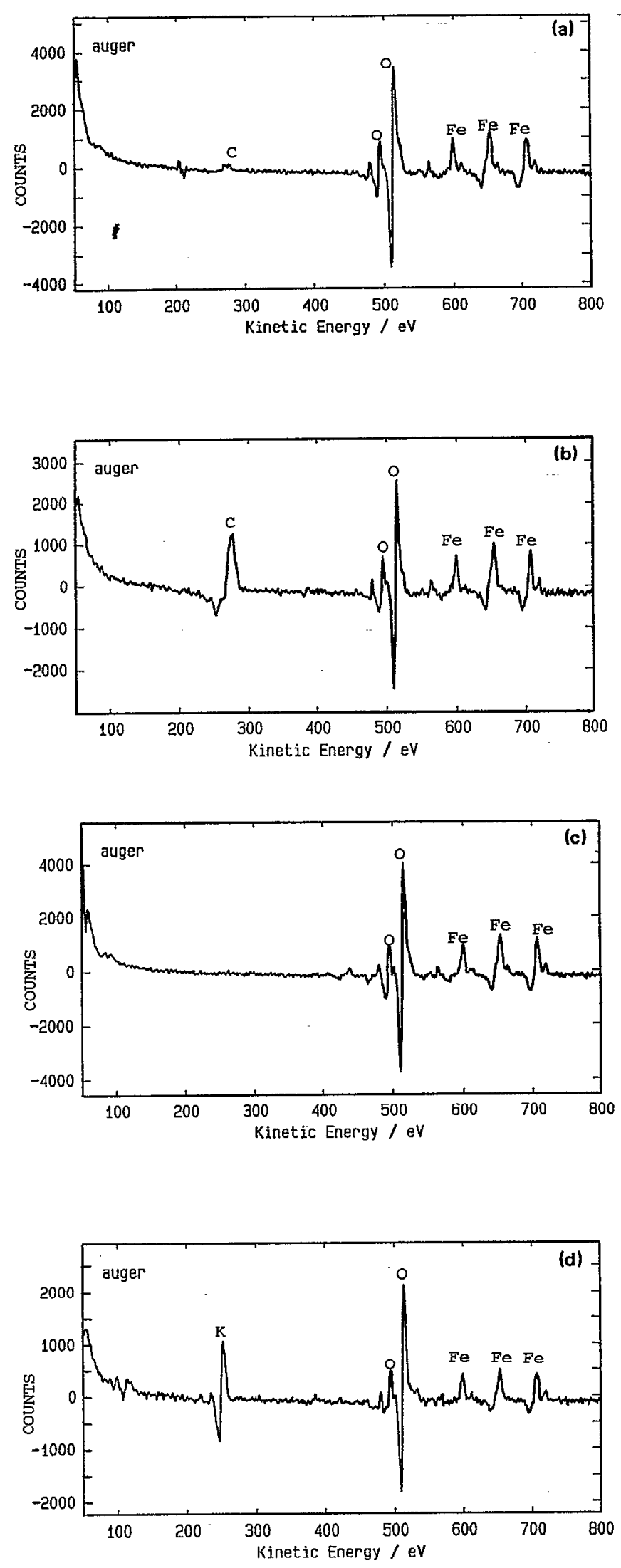

FIG. 7. (a) Auger spectrum of a mechanically polished surface of $\mathrm{Fe}_{3} \mathrm{O}_{4}$ after introduction into the UHV chamber. (b) The same sample after annealing at $500^{\circ} \mathrm{C}$ for $12 \mathrm{~h}$. The amount of carbon on the surface increases drastically. (c) After annealing at $700^{\circ} \mathrm{C}$ for $20 \mathrm{~h}$. The surface is clean. (d) After annealing at $800^{\circ} \mathrm{C}$ for $20 \mathrm{~h}$. Potassium diffused from the bulk to the surface.

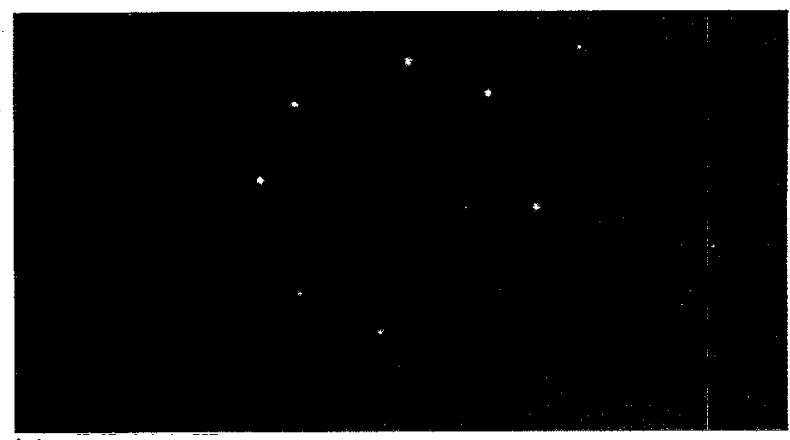

(a)

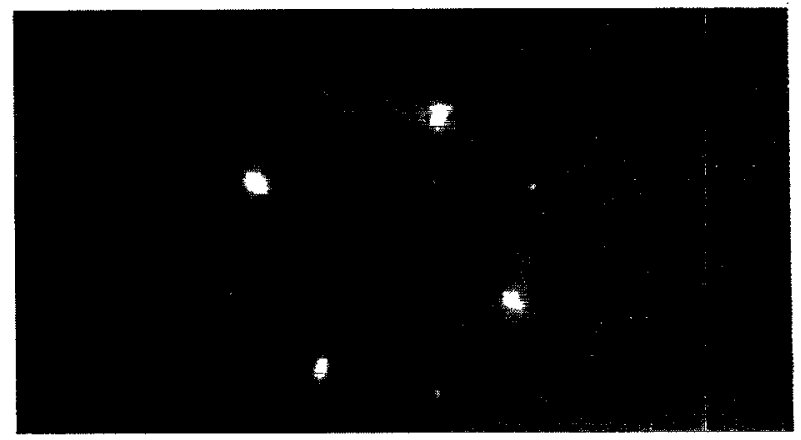

(b)

FIG. 8. LEED patterns of the (100) surface of magnetite. (a) Energy of the electron beam is $E=86 \mathrm{eV}$, (b) $E=136 \mathrm{eV}$.

\section{STM measurements on (100) surface of magnetite}

Results of the ambient STM measurements on the cleaved surface (100) of magnetite are presented in Fig. 9. We have not succeeded in getting atomic resolution images under ambient conditions using ordinary PtIr or W tips, although a set of images of the (100) surface contains traces of lines with a periodicity of $8.4 \AA$. We find a onedimensional surface superlattice with a period of $3 \mathrm{~nm}$ (Figs. 9 and 10) with the lines of the superlattice being

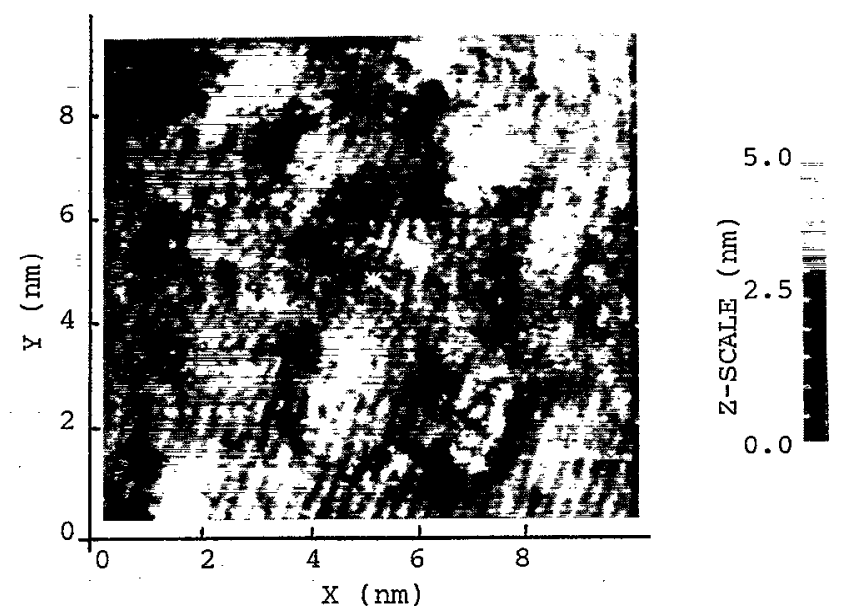

FIG. 9. One-dimensional superlattice with a period $30 \mathrm{~nm}$ on a (100) surface of magnetite. The image was obtained in air using a PtIr tip. Bias is $200 \mathrm{mV}$, setpoint current is $2 \mathrm{nA}$. 


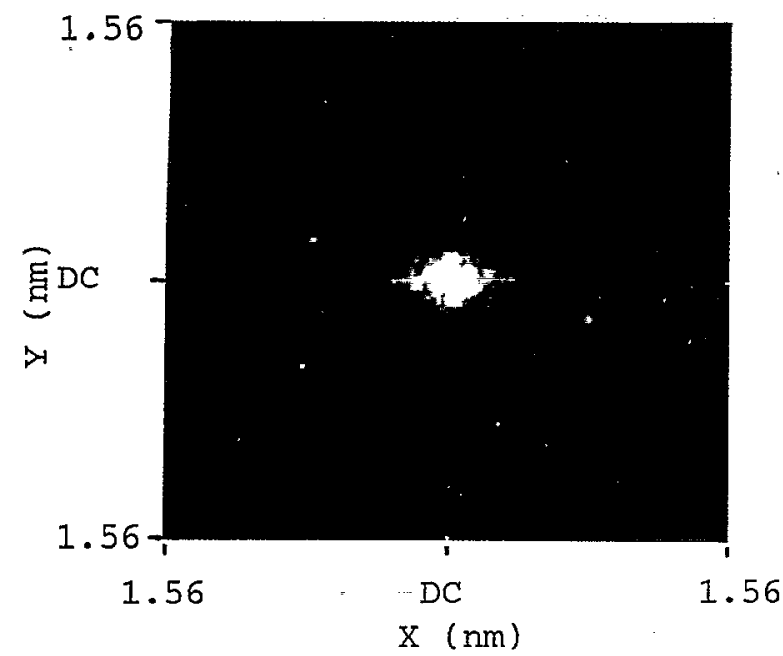

FIG. 10. Two points on the two-dimensional Fourier spectrum of the image on Fig. 9 clearly show presence of the superlattice.

aligned along (001) axis. The corrugation of the superlattice is $\approx 0.2 \mathrm{~nm}$. We could not see this superlattice on the LEED patterns. One can show that the spots corresponding to this superlattice would appear on LEED patterns at the energy of electron beam of 5-25 eV. Our LEED system did not allow us to carry out measurements at such a low energy. Similar one-dimensional superlattices were observed on the surface of high-temperature superconducting oxides $\mathrm{Bi}_{2.15} \mathrm{Sr}_{1.7} \mathrm{CaCu}_{2} \mathrm{O}_{8}$ and $\mathrm{Tl}_{2} \mathrm{Ba}_{2} \mathrm{CaCu}_{2} \mathrm{O}_{8}$ using a scanning tunneling microscope. ${ }^{85,86} \mathrm{It}$ is supposed that the superlattice is determined by deviations from the stoichiometry in the oxides.

Atomic resolution is achieved in the UHV conditions using an iron and a tungsten tip (Figs. 11 and 12). The experiments were performed with a positive bias voltage on the sample in the range $0.75-3 \mathrm{~V}$. When the bias voltage was less than $1 \mathrm{~V}$, the noise level increased drastically. This fact can be understood in connection with the results of Ref. 83. By inverse photoemission, authors of Ref. 83 observed a high density of unoccupied electronic states in the energy range $1-3 \mathrm{eV}$ above the Fermi level $E_{F}$. In the range between $E_{F}$ and $1 \mathrm{eV}$ above $E_{F}$, the density of the unoccupied states is much less.

The images clearly show the rows of the ions with the distance between the rows of $0.59 \mathrm{~nm}(5.9 \AA)$. The rows of the consequent terraces separated by a distance of $0.2 \mathrm{~nm}$, are perpendicular. The observed rows consist of iron ions at the tetrahedral positions of the spinel structure and the terraces correspond to the planes $A_{1}$ and $A_{2}$ of Fig. 6. The topmost layers of ions in the planes $A_{1}$ and $A_{2}$, are shown on the Fig. 13. One can see from Fig. 13 that the distance between the rows of oxygen ions in the planes $A_{1}$ and $A_{2}$ is only $2.95 \AA$. The fact that the oxygen sites are not visible in the STM images obtained with a positive sample bias, is a spectroscopic effect which can be explained by a dominant tunneling via the empty $\mathrm{Fe} 3 d$ states of the $\mathrm{Fe}_{3} \mathrm{O}_{4}$ (100) surface.

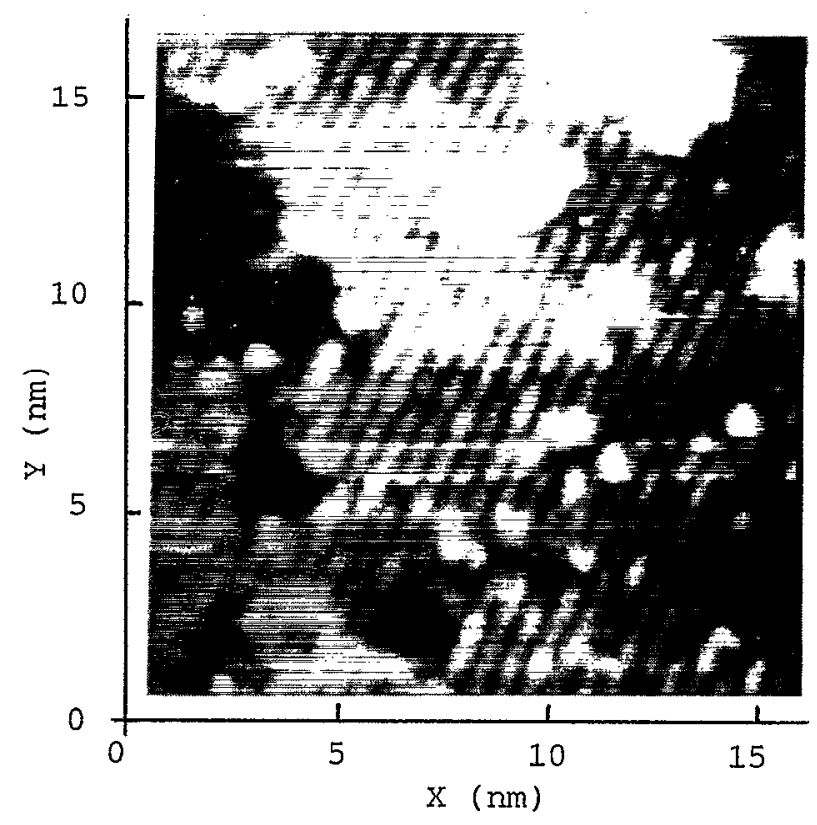

FIG. 11. Atomic resolution on a (100) surface of magnetite obtained with a UHV-STM using an iron tip. Bias is $3 \mathrm{~V}$, setpoint current is $1 \mathrm{nA}$, scan size is $15 \mathrm{~nm} \times 15 \mathrm{~nm}$. Total grey scale is $4 \mathrm{~nm}$.

\section{CONCLUSIONS}

We have suggested an approach to solve the problems in operating a spin-polarized scanning tunneling microscope. Two main points of the approach are: (1) using an antiferromagnetic STM tip and (ii) using a binary localized ferromagnet as a sample.

We listed antiferromagnetic materials which could be used as the STM tips and have shown that it is possible to prepare sharp STM tips of some of these materials and to obtain routinely atomic resolution images on a conven-

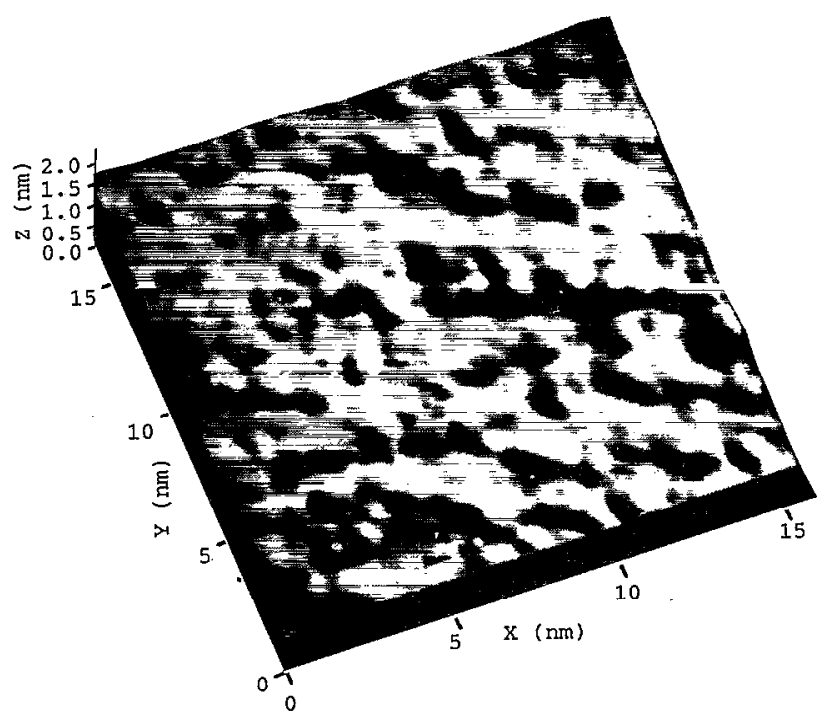

FIG. 12. Atomic resolution on a (100) surface of magnetite obtained with a UHV-STM using a tungsten tip. Bias is $3 \mathrm{~V}$, setpoint current is $1 \mathrm{nA}$, scan size is $15 \mathrm{~nm} \times 15 \mathrm{~nm}$. 


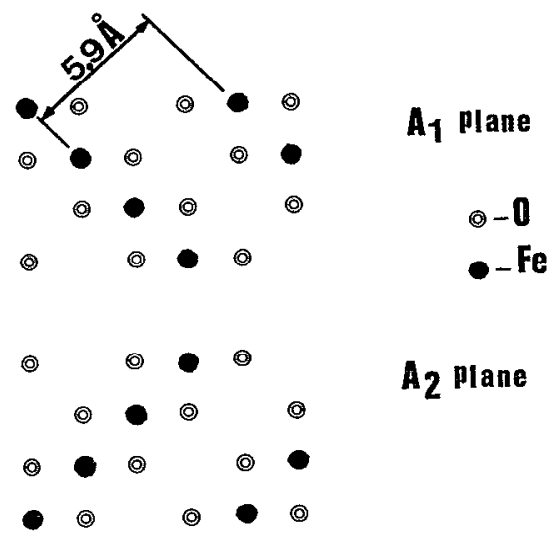

FIG. 13. Location of ions in the planes $A_{1}$ and $A_{2}$ of magnetite (see Fig. 6 ). The arrangement of the iron ions in rows, separated by the distance $5.9 \AA$, is obvious from this picture.

tional STM sample [Si(100), $\mathrm{Si}(100)]$ using these tips. We also listed binary localized ferromagnets which could be employed as a sample in the SPSTM. The compound $\mathrm{Fe}_{3} \mathrm{O}_{4}$ (magnetite) is expected to be a promising candidate for SPSTM as far as it has a large value of spin-polarization near $E_{F}$. We have found a way of preparing flat (100) surfaces of magnetic without surface contamination. For the first time we have obtained LEED patterns on (100) surface of magnetite, and have identified the nonreconstructed (100) surface.

Furthermore we obtained atomic resolution images on the (100) surface of magnetite using an iron and a tungsten tip. Contrary to early speculations, ${ }^{84}$ this is the first successful observation of atomic resolution on a ferromagnetic sample using a ferromagnetic tip. The STM images are consistent with the crystal structure of magnetite and LEED data.

Investigation of the difference between the images obtained with a magnetic and a nonmagnetic tip on a (100) surface of magnetite and STM measurements in an external magnetic field, are the topics of current research.

\section{ACKNOWLEDGMENTS}

We would like to thank Professor S. Gräser for kindly providing our best natural single crystals of magnetite as well as J. E. Frommer for proofreading the manuscript. Financial support from the Swiss National Science Foundation and the Irish Science and Technology Agency EOLAS is gratefully acknowledged.

${ }^{1}$ G. Binnig, H. Rohrer, Ch. Gerber, and E. Weibel, Appl. Phys. Lett. 40, 178 (1982).

${ }^{2}$ J. C. Slonczewski, Phys. Rev. B 39, 6995 (1988).

${ }^{3}$ M. Julliere, Phys. Lett. A 54, 225 (1975).

${ }^{4}$ D. M. Eigler and E. K. Schweizer, Nature 334, 524 (1990).

${ }^{5}$ F. Besenbacher, L. Eierdal, E. Legsgaard, and I. Stensgaarad, U1tramicroscopy (to be published).

${ }^{6} \mathrm{R}$. Wiesendanger, I. V. Shvets, D. Bïrgler, G. Tarrach, H.-J. Güntherodt, and J. M. D. Coey, Ultramicroscopy (to be published).

${ }^{7}$ R. Wiesendanger, H.-J. Güntherodt, G. Güntherodt, R. J. Gambino, and R. Ruf, Phys. Rev. Lett. 65, 247 (1990).

${ }^{8}$ M. Johnson and J. Clarke, J. Appl. Phys. 67, 6141 (1990).
${ }^{9}$ A. A. Minakov and I. V. Shvets, Surf. Sci. Lett. 236, L377 (1990).

${ }^{10}$ L. Pal, E. Kren, G. Kadar, P. Szabo, and T. Tarnoczi, J. Appl. Phys. 39, 538 (1968).

${ }^{11}$ E. Kren, G. Kadar, L. Pal, J. Solyom, P. Szabo, and T. Tarnoczi, Phys. Rev. 171, 574 (1968).

${ }^{12}$ T. Tokoyama and M. Wuttig, Z. Mettalk. 54, 308 (1963).

${ }^{13}$ J. S. Kasper and J. S. Kouvel, J. Phys. Chem. Solids 11, 231 (1959).

${ }^{14}$ B. R. Coles and W. Hume-Rothery, J. Instr. Metals 80, 85 (1951).

${ }^{15}$ W. B. Pearson, K. Brun, and A. Kjekshus, Acta Chem. Scand. 19, 477 (1965).

${ }^{16}$ F. I egrand and S. Neov, Solid State Commun. 10, 883 (1972).

${ }^{17}$ K. Brun, A. Kjekshus, and W. B. Pearson, Acta Chem. Scand. 19, 107 (1965).

${ }^{18}$ A. Giansoldati, J. O. Linde, and G. Borelius, J. Phys. Chem. Solids 11, 46 (1959).

${ }^{19}$ X. Hirone, X. Maeda, X. Tsubokawa, and X. Tsuya, J. Phys. Soc. Jpn. 11, 1083 (1956).

${ }^{20}$ W. L. Roth, J. Appl. Phys. 31, 2000 (1960).

${ }^{21}$ S. J. Pickart and R. Nathans, J. Appl. Phys. 34, 1203 (1963).

${ }^{22}$ I. Tsubokawa, J. Phys. Soc. Jpn. 14, 196 (1959).

${ }^{23}$ J. S. Kouvel, J. Phys. Chem. Solids 24, 795 (1963).

${ }^{24}$ A. E. Austin, E. Adelson, and W. H. Cloud, J. Appl. Phys. 33, 1356 (1962).

${ }^{25}$ L. M. Levinson, J. Phys. Chem. Solids 29, 1331 (1968).

${ }^{26}$ A. F. Andersen, Acta Chem. Scand. 14, 919 (1960).

${ }^{27}$ E. Hirahara and $\bar{M}$. Murakami, J. Phys. Chem. Solids 7, 281 (1958).

${ }^{28}$ E. Fawcett, Rev. Mod. Phys. 60, 209 (1988).

${ }^{29}$ L. E. Klebanoff and D. A. Shirley, Phys. Rev. B 33, 5301 (1986),

${ }^{30}$ Y. Teraoka and J. Kanamori, Physica B 91, 199 (1978).

${ }^{31}$ G. Allan, Surf. Sci. 74, 79 (1978).

${ }^{32}$ H. Ratajczak and Z. Sczaniecki, Phys. Status Solidi A 1, 171 (1970).

${ }^{33}$ X. Tarawa and K. Sato, Proc. Phys. Soc. Jpn. 18, 773 (1963).

${ }^{34}$ G. Kappel, G. Fischer, and A. Jaegle, Phys. Lett. A 45, 267 (1973).

${ }^{35}$ J. B. Forsyth and P. J. Brown, J. Phys. Condens. Matter. 2, 2713 (1990).

${ }^{36}$ R. F. Jackson, R. G. Scurlock, D. B. Utton, and E. M. Wray, Proc. Phys. Soc. 85, 127 (1965).

${ }^{37}$ A. Wrzeciono, Izv. Akad. Nauk USSR, Ser. Fiz. 28, 601 (1964).

${ }^{38}$ B. W. Roberts, Phys. Rev. 104, 607 (1956).

${ }^{39}$ H. Haudek and W. K. Unger, Phys. Status Solidi A 7, 393 (1971).

${ }^{40}$ R. R. Heikes, Phys. Rev. 99, 446 (1955).

${ }^{41}$ H. A. Alperin, B. J. Brown, and R. Nathans, J. Appl. Phys. 34, 1201 (1963).

${ }^{42}$ F. J. Darnell, W. H. Cloud, and H. S. Jarrett, Phys. Rev. 130, 647 (1963).

${ }^{43}$ P. E. Bierstedt, Phys. Rev. 132, 669 (1963).

${ }^{44}$ S. Chikazumi and K. Adachi, Handbook on Magnetic Materials (Asakura Shotku, Tokyo, 1975).

${ }^{45}$ H. Ido, J. Appl. Phys. 57, 3247 (1985).

${ }^{46}$ W. J. Takei, D. E. Cox, and G. Shirane, Phys. Rev. 129, 2008 (1963).

${ }^{47}$ Y. Yamaguchi and $H$. Watanabe, J. Magn. Magn. Mater. 31-34, 619 (1983).

${ }^{48}$ T. Okita and Y. Makino, J. Phys. Soc. Jpn. 25, 120 (1968).

${ }^{49}$ K. W. G. Wychoff, Crystal Structures (Interscience, New York, 1963).

${ }^{50}$ J. C. Wood and A. J. Nozik, Phys. Rev. B 4, 2224 (1971).

${ }^{51}$ C. Lo, S. V. Krishaswamy, L. N. Mulay, and R. A. Diffenbach, J. Appl. Phys. 53, 2745 (1982).

${ }^{52}$ R. L. Cohen, Applications of Mössbauer Spectroscopy (Academic, New York, 1980).

${ }^{53}$ E. P. Wohlfarth and K. H. J. Buschow, Ferromagnetic Materials (North-Holland, Amsterdam, 1988).

${ }^{54}$ P. J. Brown and J. L. Cox, Philos. Mag. 23, 705 (1971).

${ }^{55}$ I. D. Weisman, L. J. Swartzendruber, and L. H. Bennett, Phys. Rev. 177, 465 (1969).

${ }^{56}$ O. Kubaschewski, Iron-Binary Phase Diagrams (Springer, Berlin, 1982).

${ }^{57}$ H. Abe, H. Yasuoka, M. Matsuura, A. Hirai, and T. Shinjo, J. Phys. Soc. Jpn. 19, 1491 (1964).

${ }^{58}$ K. Kanematsu and T. Ohoyama, J. Phys. Soc. Jpn. 20, 236 (1965).

${ }^{59}$ K. Kanematsu and T. Ohoyama, J. Phys. Soc. Jpn. 18, 920 (1963).

${ }^{60}$ T. Ohoyama and K. Kanematsu, J. Phys. Soc. Jpn. 18, 589 (1963).

${ }^{61}$ H. Yamamoto, J. Phys. Soc. Jpn. 20, 2166 (1965).

${ }^{62}$ W. A. Hines, A. H. Menotti, J. I. Budnick, T. J. Burch, T. Litrenta, V. Niculescu, and K. Raj, Phys. Rev. B 13, 4060 (1976). 
${ }^{63}$ K. I. Arai, K. Ohmori, H. Miura, and T. Tsuya, J. Appl. Phys. 57, 460 (1985).

${ }^{64}$ M. B. Stearns, J. Appl. Phys. 49, 1555 (1978).

${ }^{65}$ R. Jesser, J. Phys. (Paris) 40, 23 (1979).

${ }^{60} \mathrm{R}$. Jesser, Compt. Rend. 274, 12 (1972).

${ }^{67}$ U. Gonser, M. Ron, H. Ruppersberg, W. Keune, and A. Trautwein, Phys. Status Solidi A 10, 493 (1972).

${ }^{68}$ C. Jannin, P. Lecocq, and A. Michel, Compt. Rend. 257, 1906 (1963).

${ }^{69}$ C. Djega-Mariadassou, P. Lecocq, G. Trumpy, J. Traft, and P. Ostergaard, Nuovo Cimento B 46, 35 (1966).

${ }^{70}$ K. Schwarz, J. Phys. F 16, L211 (1986).

${ }^{71}$ K. P. Kämper, W. Schmitt, G. Güntherodt, R. J. Gambino, and R. Ruf, Phys. Rev. Lett. 59, 2788 (1987).

${ }^{72}$ S. Hattori, I. Ishii, M. Shinohara, and T. Nakagawa, IEEE Trans. Magn. 15, 1549 (1979).

${ }^{73}$ V. Hoffmann, R. Schäfer, E. Appel, A. Hubert, and H. Soffel, J. Magn. Magn. Mater. 71, 90 (1987).

${ }^{74}$ S. Iida, K. Mizushima, M. Mizoguchi, K. Kose, K. Kato, K. Yanai, N. Goto, and S. Yumoto, J. Appl. Phys. 53, 2164 (1982).

${ }^{75}$ S. F. Alvarado, M. Erbudak, and P. Munz, Phys. Rev. B 14, 2740 (1976).
${ }^{76}$ S. V. Vonsovski, Magnetism (Nauka, Moscow, 1971).

${ }^{77}$ E. Kita, Y. Tokuyama, A. Tasaki, and K. Siratori, J. Magn. Magn. Mater. 31-34, 787 (1983).

${ }^{78}$ S. Iida, M. Mizoguchi, N. Goto, and Y. Motomura, J. Magn. Magn. Mater. 31-34, 771 (1983).

${ }^{79}$ R. Aragon, R. J. Rassmussen, J. P. Shepherd, J. W. Koenitzer, and J. M. Honig, J. Magn. Magn. Mater. 54-57, 1335 (1986).

${ }^{80}$ A. Yanase and K. Siratori, J. Phys. Soc. Jpn. 53, 312 (1984).

${ }^{81}$ M. Aeschlimann, G. L. Bona, F. Meier, M. Stampannoni, G. Zampieri, and H. C. Sigemanin, Appl. Phys. Lett. 49, 824 (1986).

${ }^{82}$ M. Seo, J. B. Lumsden, and R. W. Staehle, Surf. Sci. 50, 541 (1975).

${ }^{83}$ M. Sancrotti, F. Ciccacci, M. Finazzi, E. Vescovo, and S. F. Alvarado, Z. Phys. B. 84, 243 (1991).

${ }^{84}$ R. Allenspach, H. Salemink, A. Bischof, and E. Weibel, Z. Phys. B 67, 1225 (1987).

${ }^{85}$ C. K. Shih, R. M. Feenstra, J. R. Kirtley, and G. V. Chandrashekhar, Phys. Rev. B 40, 2682 (1989).

${ }^{86}$ X. L. Wu, C. M. Lieber, D. S. Ginley, and R. J. Baughman, Appl. Phys. Lett. 55, 2129 (1989). 